\title{
Global diastolic strain rate for the assessment of left ventricular diastolic dysfunction in young peritoneal dialysis patients: a case control study
}

Jing Zhu ${ }^{\dagger}$, Fei Shi ${ }^{\dagger}$, Tao You, Chao Tang and Jianchang Chen ${ }^{*}$

\begin{abstract}
Background: Left ventricular (LV) myocardial longitudinal diastolic strain rate measured by two-dimensional speckle tracking imaging (2D-STI) was proved to have a better correlation with the LV diastolic function. We aimed to use this sensitive tool to predict LV myocardial diastolic dysfunction in young peritoneal dialysis (PD) patients with preserved LV ejection fraction (LVEF).

Methods: We enrolled 30 PD patients aged $\leq 60$ with LVEF $\geq 54 \%$ and classified as normal LV diastolic function by conventional echocardiography, and 30 age- and sex-matched healthy people as the control group. The left atrial maximum volume index (LAVI), LV mass index (LVMI), LVEF, LV posterior wall thickness (LVPWT), interventricular septal thickness (IVST), peak velocity of tricuspid regurgitation (TR), peak early diastolic velocity/late diastolic velocity (by Pulsed Doppler) (E/A) and E/peak velocity of the early diastolic wave (by Pulsed-wave tissue Doppler) (E/e') were recorded by conventional echocardiographic. Next, the average LV global longitudinal systolic strain (GLS avg) and the average LV global longitudinal diastolic strain rate (DSr avg) during early diastole (DSrE avg), late diastole (DSrA avg) and isovolumic relaxation period (DSrIVR avg) were obtained from 2D-STI. Combined them with E, the new noninvasive indexes (E/DSrE avg., E/DSrA avg. and E/DSrlVR avg) were derived.

Results: The PD group 's LVEF, E/e', TR and LAVI were in the normal range compared with the controls, and only $e^{\prime}$ $(p<0.001)$ was decreased. The LVMI $(p<0.001)$, LVPWT $(p<0.001)$, IVST $(p<0.001)$ increased while E/A $(p<0.001)$ decreased. The GLS avg. ( $p=0.008$ ) was significantly decreased in PD patients compared with the controls. DSrA avg. ( $p=0.006)$ and E/DSrE avg. $(p=0.006)$ were increased, while DSrE avg. $(p<0.001)$, DSrlVR avg. $(p=0.017)$ and E/DSrA avg. $(p<0.001)$ decreased. After the multivariable regression analysis, the correlation between DSrE and the conventional parameters including LVPWT $(p<0.001)$, E/A $(p<0.001)$ still remained significant.

(Continued on next page)
\end{abstract}

\footnotetext{
* Correspondence: chenjcsz@126.com

${ }^{\dagger}$ Jing Zhu and Fei Shi contributed equally to this work.

Department of Cardiology, The Second Affiliated Hospital of Soochow

University, 1055 Sanxiang Road, Suzhou 215004, Jiangsu Province, China
}

(C) The Author(s). 2020 Open Access This article is licensed under a Creative Commons Attribution 4.0 International License, which permits use, sharing, adaptation, distribution and reproduction in any medium or format, as long as you give appropriate credit to the original author(s) and the source, provide a link to the Creative Commons licence, and indicate if changes were made. The images or other third party material in this article are included in the article's Creative Commons licence, unless indicated otherwise in a credit line to the material. If material is not included in the article's Creative Commons licence and your intended use is not permitted by statutory regulation or exceeds the permitted use, you will need to obtain permission directly from the copyright holder. To view a copy of this licence, visit http://creativecommons.org/licenses/by/4.0/ The Creative Commons Public Domain Dedication waiver (http://creativecommons.org/publicdomain/zero/1.0/) applies to the data made available in this article, unless otherwise stated in a credit line to the data. 
(Continued from previous page)

Conclusions: Young PD patients with preserved LVEF already exhibited myocardial diastolic dysfunction. Global diastolic strain rate indexes were valuable parameters to evaluate diastolic dysfunction. Additionally, LVPWT was highly correlated with DSrE, such parameter should be taken into account for predicting the early LV diastolic dysfunction in clinical practice.

Keywords: Strain rate, Diastolic dysfunction, Young peritoneal dialysis patients, Two-dimensional speckle tracking imaging

\section{Background}

Currently, more young people are developing chronic kidney disease (CKD), adding to the burden on families and countries. Peritoneal dialysis (PD) is advantageous because it preserves residual renal function and is inexpensive, with greater maneuverability outside the hospital, PD is becoming a popular choice for renal replacement therapy in young uremic patients, especially in developing countries. In the early stage of CKD, cardiac structure and function already begin to change and gradually aggravate in patients with deteriorated renal function approaching or on dialysis according to some studies [1, 2]. Until now, more and more studies have focused on studying left ventricular (LV) diastolic dysfunction because diastolic dysfunction seems to occur earlier than systolic dysfunction in PD patients. And impaired LV diastolic function has been considered as the primary determinant of symptoms related to cardiovascular events, and therefore, the incidence of sudden cardiac death, arrhythmia, and congestive heart failure tend to be higher in patients with LV diastolic dysfunction than in those without [3-5]. Thus, identifying young PD patients' diastolic dysfunction at the early stage is of clinical importance.

Cardiac catheterization is known as the gold standard to evaluate the extent of diastolic dysfunction, but it is invasive and not easily accepted by the majority of patients. In that case, noninvasive estimation of LV diastolic dysfunction is a clinical requisite. With the development of the two-dimensional speckle tracking imaging technique (2D-STI), it is now possible to use LV global longitudinal diastolic strain rate (DSr) to measure LV diastolic dysfunction indirectly and noninvasively [6-8]. Therefore, the objective of this study was to use 2D-STI to predict LV myocardial diastolic dysfunction in the preclinical phase in young PD patients with preserved LVEF.

\section{Methods}

We enrolled 30 young uremic patients who underwent PD catheter insertion in our PD center from September 2016 to September 2018; there was the equal distribution in age and sex. The inclusion criteria were as follows: (1) progression to end-stage renal disease, (2) underwent PD regularly for 3-18 months, (3) age $\leq 60$ years in order to avoid the effect of age on diastolic function [9, 10], (4) the basic rhythm was sinus rhythm, (5) the LV ejection fraction (LVEF) was $\geq 54 \%$ [11], and (6) LV diastolic function was classified as normal by conventional echocardiography [10]. We excluded patients with nonsinus rhythm, congenital heart disease, primary valvular heart disease, moderate or severe mitral and aortic regurgitation, heart block, pacemaker implantation, hypertensive heart disease, having had acute myocardial infarction or acute heart failure, regional wall motion abnormality detected by echocardiography, any other nonrenal heart diseases, moderate and severe anemia, and unsatisfactory echocardiographic images. Furthermore, 30 age- and sex-matched healthy people were chosen for the normal control group, who were free of heart and kidney disease by confirmation with electrocardiogram, echocardiography, routine blood and urine examination, and renal function (normal serum creatinine (CREA) and blood urea nitrogen (BUN)).

Firstly, some baseline characteristics of the study subjects were collected, including age, sex, body mass index (BMI), body surface area (BSA), blood pressure, peritoneal dialysis time, CREA, BUN, hemoglobin $(\mathrm{Hb})$, calcium $(\mathrm{Ca})$, phosphorus $(\mathrm{P})$, and the causes of end stage renal disease (ESRD). Then, studies were performed using a Model GE Vivid E9 ultrasound system with an M5S phased array transducer using a transmission frequency of $2.0-4.5 \mathrm{MHz}$. Images were taken of the parasternal view with patients lying in the left decubitus position. Using M-mode echocardiography, we recorded the LV internal diameter at end-diastole (LVIDD), LV internal diameter at endsystole (LVIDS), interventricular septal thickness (IVST), and LV posterior wall thickness (LVPWT). The LVEF was calculated using a modified Simpson's biplane method, and the LA maximum volume (LAVmax) was obtained just before mitral valve opening using an area-length method from the apical 4- and 2-chamber views. All cardiac chamber volumes and diameter were indexed to the body surface area (BSA), and the normal systolic function was defined as an $\mathrm{LVEF} \geq 54 \%$ [11]. 
Then, we calculated LV mass: LV mass $(\mathrm{g})=0.8 \times$ $1.04 \times\left[\left(\right.\right.$ LVIDD + LVPWT + IVST $^{3}-$ LVIDD $\left.^{3}\right]+0.6$ [11], and defined the LV mass index (LVMI) as the LV mass/height ${ }^{2.7}$ [12]. The peak early diastolic velocity (E), late diastolic velocity (A) of the mitral orifice and E deceleration time (DT) of the E-wave were measured by pulsed Doppler from the apical 4chamber view. Then, the E/A ratio was calculated. The peak velocity of the early $\left(e^{\prime}\right)$ and late $\left(a^{\prime}\right)$ diastolic wave were measured by pulsed-wave tissue Doppler, with the sample volume close to the mitral valve annulus in the apical 4-chamber view in the lateral wall. The peak velocity of tricuspid regurgitation (TR) was achieved in the apical four-chamber view with continuous-wave Doppler. We calculated the E/e ', and defined e' $<10 \mathrm{~cm} / \mathrm{s}, \mathrm{E} / \mathrm{e}^{\prime}>13, \mathrm{TR}>2.8 \mathrm{~m} / \mathrm{s}$ and LAVI $>34 \mathrm{~mL} / \mathrm{m}^{2}$ as the recommended variables for identifying diastolic dysfunction. If more than half of the available variables do not meet the cutoff values for identifying abnormal function, the LV diastolic function was classified as normal [10]. All echocardiographic measurements were performed by experienced echocardiographic technicians who were blinded to the clinical conditions.

Next, dynamic 2D sonographic images of 3 cardiac cycles were obtained from the standard apical longaxis view, 4- and 2-chamber views. These images were digitally stored on hard disks for myocardial strain analysis using offline software EchoPAC 201. Manual tracings of the endocardial border during end-systole in 3 apical views were performed, and when the system automatically determined the tracking quality for each analyzed segment, the average of global longitudinal systolic strain (GLS avg) was automatically obtained. Then, from the LV longitudinal diastolic strain rate curves for three views of the $\mathrm{LV}$ myocardial: the LV longitudinal diastolic strain rate (DSr) during early diastole (DSrE), during late diastole (DSrA), and during the isovolumic relaxation period (DSrIVR) from the apical long-axis view, 4- and 2chamber views (Fig. 1). We collected these parameters and calculated their average, and combined with E, the diastolic indices E/DSrIVR avg., E/DSrA avg., and E/DSrE avg. were obtained.

Lastly, variates were presented as the mean \pm standard deviation, median with interquartile range, or number with percentage. Continuous variates with normal and skewed distributions were compared using the paired $t$ test and Wilcoxon rank-sum test, respectively. Categorical variates were compared using the $x^{2}$ test. The correlation between two variates was determined by Pearson's linear correlation and visualized by scatter plots. To avoid the influence of the multicollinearity between parameters, stepwise multivariate linear regression was constructed to estimate the association between DSrE and conventional echocardiography parameters. Moreover, internal validation was performed using at least 1000 bootstrap samples. Statistical analysis was performed using SPSS software (version 22, IBM, USA). A $P$ value $<0.05$ was considered as statistically significant.

\section{Results}

A total of 30 patients were included, and their average PD time was 11 months. In our study, no significant differences were found in subjects' age $(p=0.718)$, BMI $(p=0.353)$, BSA $(p=0.371)$ and Ca $(p=0.445)$. The SBP $(p=0.008)$, DBP $(p=0.002)$, CREA $(p<0.001)$, BUN $(p<0.001)$ and $\mathrm{P}(p<0.001)$ in young PD patients were significantly increased, while $\mathrm{Hb}(p<0.001)$ were decreased. The underlying causes of end stage renal disease (ESRD) were glomerulonephritis in 56.6\%, hypertensive nephrosclerosis in $16.7 \%$, diabetic nephropathy in $10 \%$, polycystic kidney in $6.7 \%$, nephrotic syndrome in $3.3 \%$, and not identified in $6.7 \%$ of patients. Overall, $76.7 \%$ of the patients were using $\mathrm{Ca}^{2+}$ channel blockers, $60 \%$ were using diuretics and 63.3\% were using $\alpha$-receptor blockers (Table 1 ).

The conventional echocardiography parameters and speckle tracking imaging parameters are shown in Table 2. PD group's E/e', TR and LAVI were in the normal range. The LVEF $(p=0.053), \mathrm{E} / \mathrm{e}^{\prime}(p=0.262)$, TR $(p=0.465)$ and LA volume index $(p=0.209)$ had no significant difference compared with the controls, while $\mathrm{e}^{\prime}(p<0.001)$ was significantly decreased. Furthermore, LVIDS/BSA ( $p=0.049)$, LVMI $(p<0.001)$, LVPWT $(p<0.001)$, IVST $(p<0.001)$ increased significantly, but had reduced $\mathrm{E}(p<0.001)$ and $\mathrm{E} / \mathrm{A}$ $(p<0.001)$. And DT $(p=0.334)$, LVIDD/BSA $(p=$ 0.054 ) had no significant difference between the groups. In strain and strain rate, GLS avg. was decreased significantly $(p=0.008)$, while it was still in the normal range. And the DSrIVR avg. $(p=0.017)$, DSrE avg. $(p<0.001)$, E/DSrE avg. $(p=0.006)$, DSrA avg. $(p=0.006)$, and E/DSrA avg. $(p<0.001)$ were significantly different from controls, while E/DSrIVR avg. $(p=0.644)$ showed no significant difference (Table 2).

Association between DSrE and conventional echocardiography parameters are shown in Table 3 and Fig. 2. In Pearson analysis, DSrE had a strong correlation with $\mathrm{E}(\mathrm{r}=0.690, p<0.001), \mathrm{e}^{\prime}(\mathrm{r}=0.742, p<0.001), \mathrm{E} / \mathrm{A}(\mathrm{r}=$ $0.747, p<0.001)$, and LVPWT $(\mathrm{r}=-0.608, p<0.001)$. And after stepwise multivariate linear regression, the correlations between DSrE and LVPWT $(p<0.001)$, E/A $(p<0.001)$ still made sense.

Figure 3 displays contour plot showing the association among DSrE, LVPWT and E/A. The results showed that 


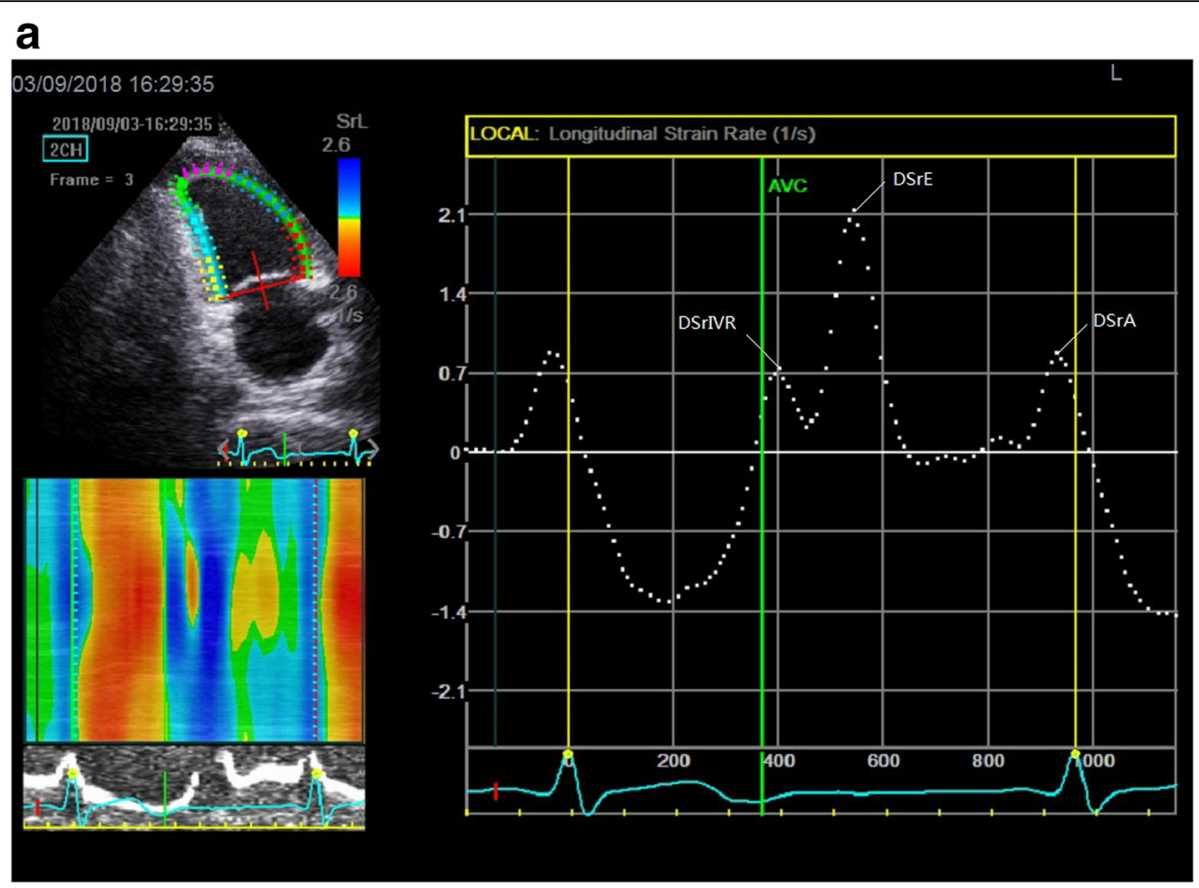

b

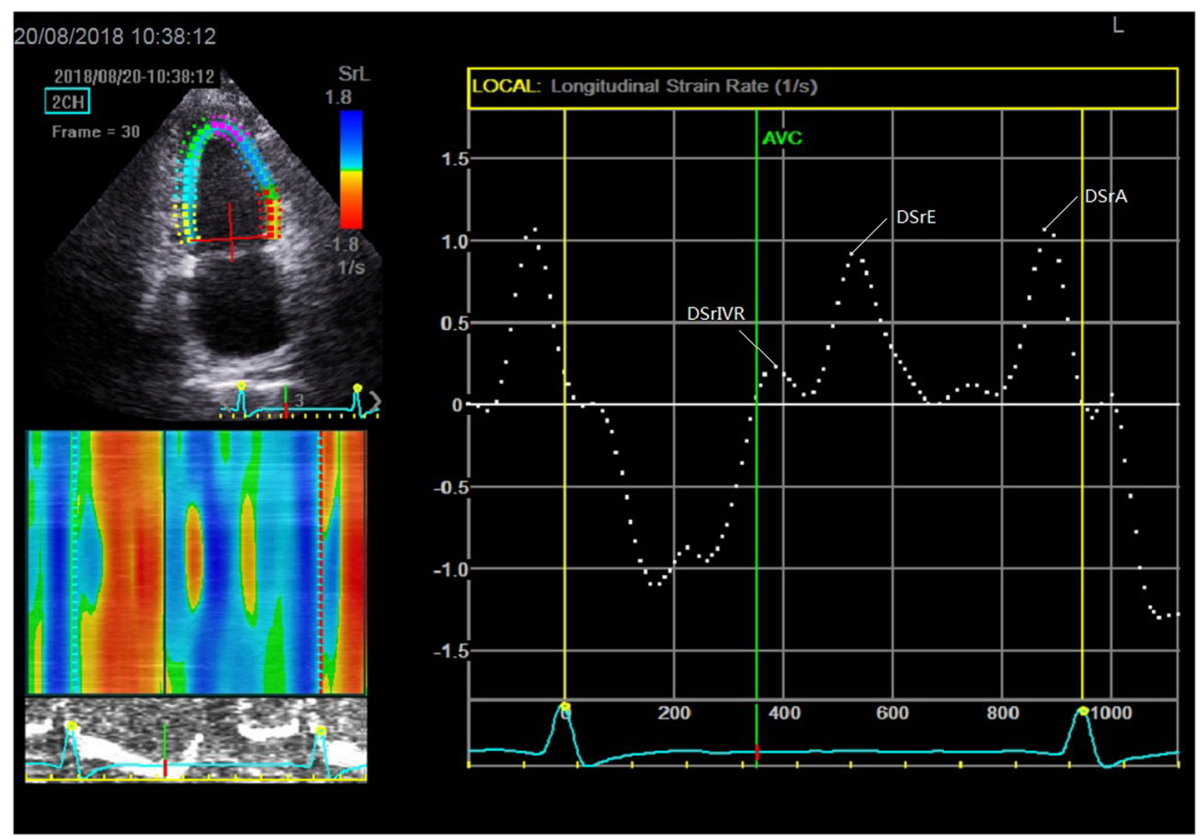

Fig. 1 Left ventricular longitudinal diastolic strain rate curves during early diastole (DSrE), late diastole (DSrA) and the isovolumic relaxation period (DSrIVR) obtained from the 2-chamber views. (a was the control group and b was the PD group)

higher E/A was consistently associated with higher DSrE after controlling for the association between E/A and LVPWT. The LVPWT was higher and more diversified in PD patients than in the healthy control group. The patients showed E/A with lower level and distribution width regarding the control group.

\section{Discussion}

It appears that nonatherosclerotic processes, including left ventricular hypertrophy and fibrosis, account for most of the excess cardiovascular risk in uremic patients [13]. Equally, the increased pressure, volume overload, anemia, hypocalcemia, and hyperphosphatemia usually 
Table 1 The Comparison of clinical characteristics in patients and controls

\begin{tabular}{|c|c|c|c|}
\hline Variable & $\begin{array}{l}\text { Control } \\
n=30\end{array}$ & $\begin{array}{l}\text { Case } \\
n=30\end{array}$ & $P$-value \\
\hline Age, years & $44.6 \pm 10.4$ & $44.8 \pm 9.5$ & 0.718 \\
\hline Men, n (\%) & 19 (63.3\%) & $19(63.3 \%)$ & \\
\hline PD time, months & - & $11(3-18)$ & \\
\hline $\mathrm{BMI}, \mathrm{kg} / \mathrm{m}^{2}$ & $22.35 \pm 2.39$ & $22.94 \pm 2.72$ & 0.353 \\
\hline $\mathrm{BSA}, \mathrm{m}^{2}$ & $1.655(1.527,1.870)^{a}$ & $1.663(1.501,1.763)$ & 0.371 \\
\hline $\mathrm{SBP}, \mathrm{mmHg}$ & $119.6 \pm 12.60$ & $135.1 \pm 26.31$ & 0.008 \\
\hline $\mathrm{DBP}, \mathrm{mmHg}$ & $74.8 \pm 7.87$ & $84.2 \pm 11.34$ & 0.002 \\
\hline CREA, umol/L & $60.6 \pm 12.25$ & $937.2 \pm 318.33$ & $<0.001$ \\
\hline $\mathrm{BUN}, \mathrm{mmol} / \mathrm{L}$ & $4.9 \pm 1.16$ & $20.0 \pm 6.94$ & $<0.001$ \\
\hline $\mathrm{Ca}, \mathrm{mmol} / \mathrm{L}$ & $2.22 \pm 0.13$ & $2.18 \pm 0.22$ & 0.445 \\
\hline $\mathrm{P}, \mathrm{mmol} / \mathrm{L}$ & $1.11 \pm 0.23$ & $1.76 \pm 0.58$ & $<0.001$ \\
\hline $\mathrm{Hb}, \mathrm{g} / \mathrm{L}$ & $135 \pm 15.0$ & $108 \pm 13.8$ & $<0.001$ \\
\hline \multicolumn{4}{|l|}{ Cause of ESRD } \\
\hline Glomerulonephritis & & $17(56.6 \%)$ & \\
\hline Diabetic nephropathy & & $3(10 \%)$ & \\
\hline Hypertensive nephrosclerosis & & $5(16.7 \%)$ & \\
\hline Polycystic kidney & & $2(6.7 \%)$ & \\
\hline Nephrotic syndrome & & $1(3.3 \%)$ & \\
\hline Unknown & & $2(6.7 \%)$ & \\
\hline \multicolumn{4}{|l|}{ Medication use } \\
\hline Diuretics & & $18(60 \%)$ & \\
\hline RAAS blockers & & $15(50 \%)$ & \\
\hline $\mathrm{Ca}^{2+}$ channel blockers & & $23(76.7 \%)$ & \\
\hline a-Receptor blockers & & 19 (63.3\%) & \\
\hline$\beta$-Receptor blockers & & $15(50 \%)$ & \\
\hline
\end{tabular}

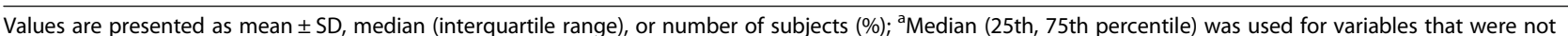
distributed normally, $P D$ peritoneal dialysis, $B M I$ body mass index, $B S A$ body surface area, $S B P$ systolic blood pressure, $D B P$ diastolic blood pressure, $C R E A$ serum creatinine, $B U N$ blood urea nitrogen, $C a$ calcium, $P$ phosphorus, $H b$ hemoglobin, ESRD end stage renal disease, $R A A S$ renin-angiotensin-aldosterone system

result in compensatory myocardial hypertrophy and fibrosis, making diastolic dysfunction seem to be more common and occur earlier than systolic dysfunction in young uremic patients [14-16]. Furthermore, in our previous study, we found that patients with the normal LVEF, although under long-term regular peritoneal dialysis, maintaining well-controlled blood pressure and stable ultrafiltration and adequate total fluid removal, their LV diastolic function deteriorated as the CKD progressed, in contrast to the stable LV systolic function [17]. Therefore, it seems important to detect diastolic dysfunction at the early stage of peritoneal dialysis.

According to guideline [10], our PD patients do not meet the diagnostic criteria for LV diastolic dysfunction. And considering the accuracy of e' may be limited for several reasons such as angle, LA pressure, mitral valve disease and annular calcification, e' cannot exactly reflect the global LV relaxation in patients with LV hypertrophy or heart failure with preserved LVEF, or in which the incidence of cardiac valve calcification is high and regional systolic dysfunction is present $[6,18-20]$. Therefore, using e' to reflect the global LV diastolic dysfunction is unsuitable. Moreover, the wall thickness of the LV ventricular such as IVST, LVPWT and LVMI in PD patients were significantly increased compared to controls, showing that the patients we studied already exhibited myocardial hypertrophy, which is a strong and independent factor for cardiovascular risk [13, 21]. Additionally, GLS is usually decreased in patients with heart failure with preserved ejection fraction, and is significantly correlated with LV end-diastolic pressure (LVEDP), showing that the decrease of GLS usually foreshadows LV diastolic dysfunction at the early stage [10]. In our study, GLS in young PD patients was in the normal range, but lower than that in the control group, indicating that LV diastolic dysfunction probably exists at the early stage of 
Table 2 The Comparison of conventional echocardiography parameters and speckle tracking imaging parameters in patients and controls

\begin{tabular}{|c|c|c|c|}
\hline Variable & $\begin{array}{l}\text { Control } \\
n=30\end{array}$ & $\begin{array}{l}\text { Case } \\
n=30\end{array}$ & $P$-value \\
\hline \multicolumn{4}{|c|}{ LV and LA structure and function } \\
\hline LVEF, \% & $68.14(64 \cdot 0,71.0)^{a}$ & $63.86(58.63,70.31)$ & 0.053 \\
\hline LVIDD, mm & $48.75(45.30,50.78)^{a}$ & $49.25(45.00,53.46)$ & 0.082 \\
\hline LVIDD/BSA, mm/m² & $28.53 \pm 2.72$ & $30.01 \pm 3.04$ & 0.054 \\
\hline LVIDS, mm & $29.94 \pm 3.47$ & $31.82 \pm 5.43$ & 0.084 \\
\hline LVIDS/BSA, mm/m² & $17.87 \pm 2.33$ & $19.24 \pm 3.01$ & 0.049 \\
\hline IVST, mm & $9.0(8.0,10.0)^{a}$ & $10.3(8.9,12.8)$ & $<0.001$ \\
\hline LVPWT, mm & $8.3(7.98,9.70)^{\mathrm{a}}$ & $10.1(9.0,11.75)$ & $<0.001$ \\
\hline LVMI, g/m 2.7 & $35.02 \pm 7.13$ & $50.62 \pm 15.67$ & $<0.001$ \\
\hline \multicolumn{4}{|l|}{ LV diastolic function } \\
\hline $\mathrm{E}, \mathrm{m} / \mathrm{s}$ & $0.91 \pm 0.22$ & $0.69 \pm 0.15$ & $<0.001$ \\
\hline $\mathrm{A}, \mathrm{m} / \mathrm{s}$ & $0.66 \pm 0.15$ & $0.82 \pm 0.16$ & $<0.001$ \\
\hline $\mathrm{e}^{\prime}, \mathrm{cm} / \mathrm{s}$ & $14.5(12,17)^{\mathrm{a}}$ & $9.0(7.75,13.0)$ & $<0.001$ \\
\hline E/A & $1.3(1.13,1.85)^{\mathrm{a}}$ & $0.8(0.70,0.98)$ & $<0.001$ \\
\hline$E / e^{\prime}$ & $6.3(5.29,7.61)^{a}$ & $7.0(5.25,9.04)$ & 0.262 \\
\hline DT, ms & $221 \pm 47$ & $233 \pm 50$ & 0.334 \\
\hline $\mathrm{TR}, \mathrm{m} / \mathrm{s}$ & $2.2(2.0,2.42)^{a}$ & $2.1(1.98,2.36)$ & 0.465 \\
\hline$L A V I, m L / m^{2}$ & $21.84 \pm 5.12$ & $23.68 \pm 6.47$ & 0.209 \\
\hline \multicolumn{4}{|c|}{ Myocardial deformation indices } \\
\hline DSrlVR avg., $\mathrm{s}^{-1}$ & $0.518 \pm 0.194$ & $0.398 \pm 0.185$ & 0.017 \\
\hline E/DSrlVR avg & $1.953(1.300,2.525)^{a}$ & $1.763(1.291,2.618)$ & 0.644 \\
\hline DSrE avg., $s^{-1}$ & $1.803(1.426,2.104)^{a}$ & $1.043(0.823,1.509)$ & $<0.001$ \\
\hline E/DSrE avg & $0.487(0.433,0.562)^{a}$ & $0.610(0.532,0.746)$ & 0.006 \\
\hline DSrA avg., $\mathrm{s}^{-1}$ & $0.925 \pm 0.281$ & $1.116 \pm 0.318$ & 0.006 \\
\hline E/DSrA avg & $1.119 \pm 0.537$ & $0.673 \pm 0.254$ & $<0.001$ \\
\hline GLS avg & $-22.50 \pm 2.511$ & $-20.36 \pm 2.827$ & 0.008 \\
\hline
\end{tabular}

Values are presented as mean \pm SD; ${ }^{a}$ Median (25th, 75th percentile) was used for variables that were not distributed normally, $L V E F$ left ventricular ejection fraction, LVIDD left ventricular internal diameter at end-diastole, LVIDS left ventricular internal diameter at end-systole, IVST interventricular septal thickness, LVPWT left ventricular posterior wall thickness, BSA body surface area, LVMI left ventricular mass index, $E$ peak early diastolic velocity (by Pulsed Doppler), $A$ late diastolic velocity (by Pulsed Doppler), e', peak velocity of the early diastolic wave (by Pulsed-wave tissue Doppler), DT deceleration time of the E-wave (by pulsed Doppler), $T R$ the peak velocity of tricuspid regurgitation (by Continuous-wave Doppler), LAVI the LA maximum volume index, DSrIVR strain rate during the isovolumic relaxation, DSrE early diastolic strain rate, DSrA late diastolic strain rate, GLS global longitudinal systolic strain, avg. average

peritoneal dialysis. So we urgently needed some sensitive indicators to quantitatively assess early LV diastolic dysfunction.

LVEDP measured by cardiac catheterization and the cardiac catheterization-derived time constant of LV relaxation, (T), are important factors for evaluating the severity of diastolic dysfunction [22]. And the late gadolinium enhancement (LGE) cardiac magnetic resonance (CMR) imaging is the gold standard to assess myocardial fibrosis and function. However, cardiac catheterization is invasive, and the contrast agents in LGE CMR are contraindicated for patients with endstage renal disease, making them of great limitation in clinical application. Global diastolic strain rate index derived by 2D-STI is confirmed to have a strong correlation with myocardial fibrosis defined by LGE CMR and haemodynamic indices (T and LVEDP) both in patients and in animal models, it is less angle and load dependent and not influenced by valvular pathology [23]. And the guideline also indicated this novel parameter has been used in conjunction with mitral E velocity to estimate LV filling pressures and to predict outcomes in several disease states [10]. So global diastolic strain rate index reveals higher accuracy in diagnosing diastolic dysfunction and the degree of myocardial fibrosis in PD patients [5, 24-27].

In our study, we found that diastolic strain rate index in young $\mathrm{PD}$ patients is significantly different as 
Table 3 The association between DSrE and conventional echocardiography parameters

\begin{tabular}{|c|c|c|c|c|c|}
\hline & DSrE avg. Univariable pearson's $r$ & $P$ & $\begin{array}{l}\text { Multivariable } \\
\text { Unstandardized } \beta\end{array}$ & Standardized $\beta$ & $P$-value \\
\hline age & -0.350 & 0.006 & & & \\
\hline TR & 0.114 & 0.386 & & & \\
\hline LVEF & 0.174 & 0.184 & & & \\
\hline $\mathrm{E}$ & 0.690 & $<0.001$ & & & \\
\hline A & -0.520 & $<0.001$ & & & \\
\hline DT & -0.069 & 0.603 & & & \\
\hline$e^{\prime}$ & 0.742 & $<0.001$ & & & \\
\hline$a^{\prime}$ & -0.359 & 0.005 & & & \\
\hline$E / A$ & 0.747 & $<0.001$ & 0.562 & 0.596 & $<0.001$ \\
\hline$E / e^{\prime}$ & -0.278 & 0.031 & & & \\
\hline LVIDD & -0.333 & 0.009 & & & \\
\hline LVIDS & -0.261 & 0.044 & & & \\
\hline IVST & -0.525 & $<0.001$ & & & \\
\hline LVPWT & -0.608 & $<0.001$ & -0.116 & -0.352 & $<0.001$ \\
\hline LVMI & -0.524 & $<0.001$ & & & \\
\hline LVIDd/BSA & -0.063 & 0.633 & & & \\
\hline LVIDS/BSA & -0.074 & 0.572 & & & \\
\hline LAVI & -0.272 & 0.035 & & & \\
\hline
\end{tabular}

$T R$ the peak velocity of tricuspid regurgitation (by Continuous-wave Doppler), LVEF left ventricular ejection fraction, E, peak early diastolic velocity (by Pulsed Doppler); A, late diastolic velocity (by Pulsed Doppler), DT deceleration time of the E-wave (by pulsed Doppler), e', peak velocity of the early diastolic wave (by Pulsed-wave tissue Doppler), a', peak velocity of the late diastolic wave (by Pulsed-wave tissue Doppler), LVIDD left ventricular internal diameter at end-diastole, LVIDS left ventricular internal diameter at end-systole, IVST interventricular septal thickness, LVPWT left ventricular posterior wall thickness, LVMI left ventricular mass index, BSA body surface area, LAVI the LA maximum volume index, DSrE early diastolic strain rate

compared to the age- and sex-matched controls, and the severity of diastolic dysfunction was associated both with low diastolic strain rate index, as other studies previously reported [6, 28]. Combined with E, E/DSrE still had a significant difference, confirming that LV diastolic dysfunction does exist at the early stage of peritoneal dialysis in young uremic patients.

We also found that there was a significant difference in DSrA, and E/DSrA between the two groups, which is in accordance with the known idea that LA function is closely coupled to LV diastolic function, and the increase in LA function is thought to be a mechanism counterbalancing the progression of LV diastolic dysfunction [7, 29]. In the presence of normal LA pressure, this shifts a greater proportion of LV filling to late diastole after atrial contraction in order to maintain the early filling pressures. From another point of view, the decrease in the ratio of E/DSrA may suggest that potential diastolic dysfunction may exist in young PD patients at the early stage [30].

By using stepwise multivariate linear regression, we estimated the association between diastolic strain rate index and conventional echocardiography parameters. We found that DSrE has a strong relationship with LVPWT and E/A. Considering the limitations of E/A, such as E/A ratio is age dependent, and the U-shaped relation between $\mathrm{E} / \mathrm{A}$ and $\mathrm{LV}$ diastolic function may make it difficult to differentiate normal pseudonormal filling, particularly with normal LVEF [10], leading to E/A unsuitable for our case. Our study suggested that for clinical purposes, when patients are not yet diagnosed with LV diastolic dysfunction by conventional echocardiography suggested by guideline, the increase in LV wall thickness should be considered as risk factors. Previous studies have confirmed the important clinical significance of LVPWT, it is an independent risk factor for paroxysmal atrial fibrillation [31], and is significantly higher than those with dipper hypertension [32], and also highly reproducible measurements used as part of a multimodality approach when assessing morphologic LV preparedness in patients with CCTGA undergoing anatomic repair [33]. AS we know, LV hypertrophy can occur at the early stage of end-stage renal disease, so we highly recommended that the combined assessment of the DSrE and LVPWT should be taken into account to evaluate abnormal LV diastolic function at the early stage [30].

Our study had its strengths. First, this was an original study performed by a group of researchers who were one of the first to focus on LV diastolic function 

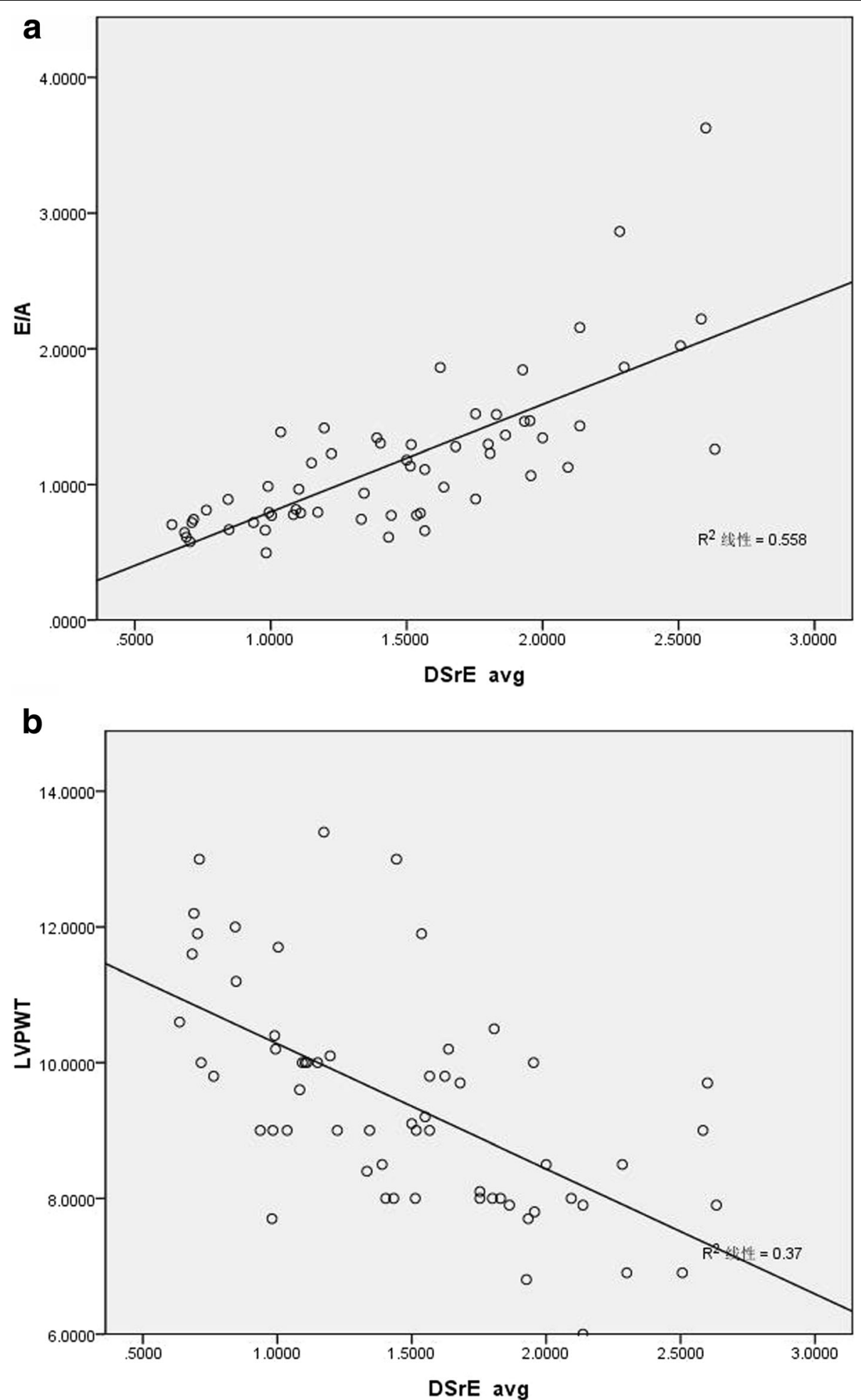

Fig. $\mathbf{2}$ a showed the correlation of DSrE with E/A, and $\mathbf{b}$ showed the correlation with LVPWT

in young PD patients. Second, we used novel and noninvasive measurements to evaluate LV diastolic dysfunction that may be detected in a preclinical phase. Third, we elucidated the possible relationship between the strain rate and conventional echocardiography parameters, making it possible and more reliable to predict the LV diastolic dysfunction by observing conventional echocardiography parameters. One limitation of our study was the small 


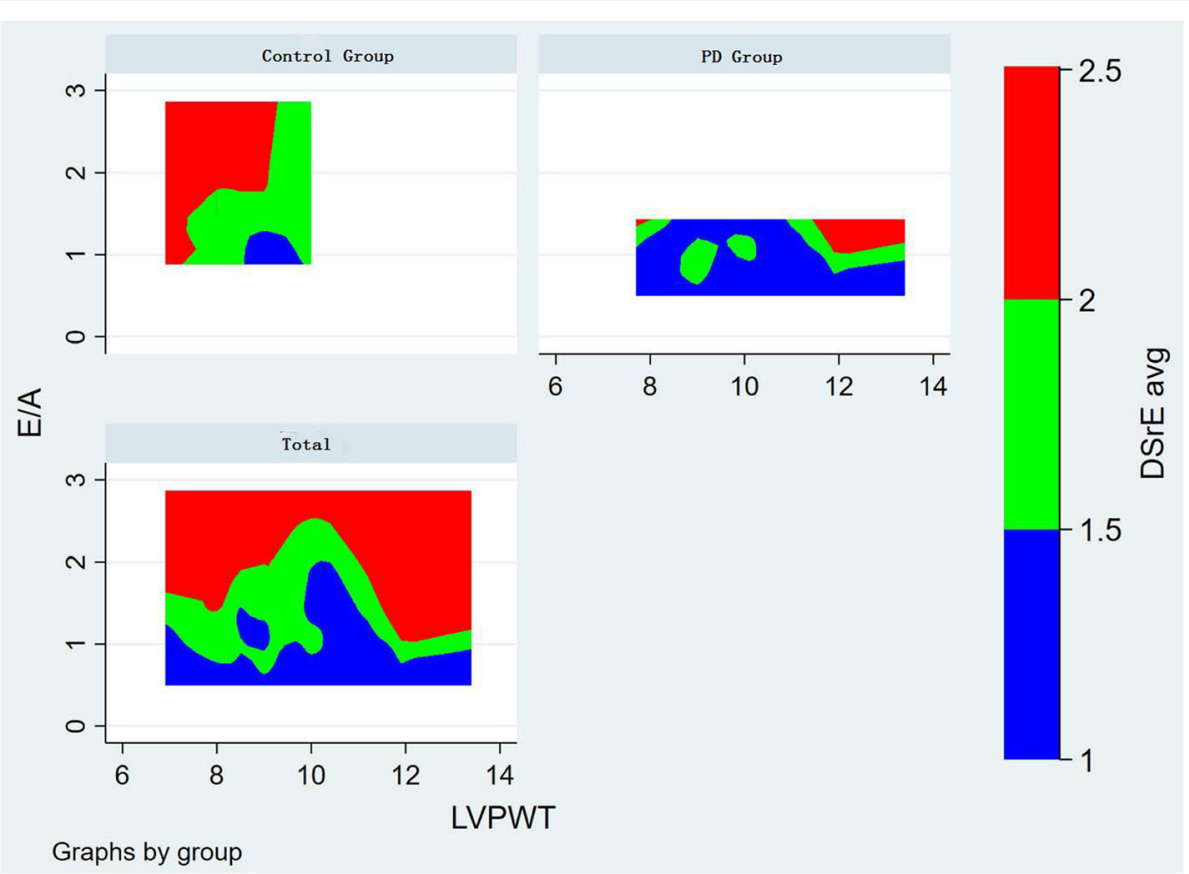

Fig. 3 Contour plot showing the correlation among DSrE with E/A, LVPWT. The vertical axis represents E/A, and the horizontal axis represents LVPWT. The results showed that higher E/A was consistently associated with higher DSrE after controlling for the association between E/A and LVPWT. The LVPWT was higher and more diversified in PD patients than in the healthy control group. The patients showed E/A with lower level and distribution width regarding the control group

sample size, and that it was only a single-center observational and cross-sectional study. Our study subsequently did not have the hemodynamic parameters obtained by cardiac catheterization as standards to compare data. And how much of diastolic abnormalities were due to reduced GLS avg. versus intrinsic diastolic dysfunction was difficult to ascertain. Moreover, our study just simply provided a sensitive tool to early diagnosis of diastolic dysfunction.

\section{Conclusion}

Despite the preserved LVEF and so-called normal diastolic function parameters that are revealed by conventional echocardiography, it was determined that young PD patients had already developed diastolic dysfunction compared with the controls. Diastolic strain rate index based on 2D-STI could be used to evaluate early LV diastolic function, and multi parameter analysis including LVPWT should be taken into account when predicting the LV diastolic dysfunction in clinical practice. If some of them indicated abnormality, preventative measures should be implemented to diminish diastolic dysfunction and thus mortality and cardiovascular events.

\section{Abbreviations}

2D-STI: Two-dimensional speckle tracking imaging; A: Late diastolic velocity (by Pulsed Doppler); a': Peak velocity of the late diastolic wave (by Pulsedwave tissue Doppler); BMI: Body mass index; BSA: Body surface area; BUN: Blood urea nitrogen; Ca: Calcium; CKD: Chronic kidney disease;
CMR: Cardiac magnetic resonance; CREA: Serum creatinine: DBP: Diastolic blood pressure; DSr avg.: Average LV global longitudinal diastolic strain rate; DSrA: DSr during late diastole; DSrE: DSr during early diastole; DSrIVR: DSr during isovolumic relaxation period; DT: Deceleration time of the E-wave (by pulsed Doppler); E: Peak early diastolic velocity (by Pulsed Doppler); e': Peak velocity of the early diastolic wave (by Pulsed-wave tissue Doppler); ESRD: End stage renal disease; GLS avg.: Average LV global longitudinal systolic strain; Hb: Hemoglobin; IVST: Interventricular septal thickness;

LAVI: Left atrial maximum volume index; LGE: Late gadolinium enhancement; LV: Left ventricular; LVEDP: LV end-diastolic pressure; LVEF: LV ejection fraction; LVIDD: Left ventricular internal diameter at end-diastole; LVIDS: Left ventricular internal diameter at end-systole; LVMI: LV mass index; LVPWT: LV posterior wall thickness; P: Phosphorus; PD: Peritoneal dialysis; RAAS: Reninangiotensin-aldosterone system; SBP: Systolic blood pressure; TR: Peak velocity of tricuspid regurgitation (by Continuous-wave Doppler)

\section{Acknowledgements}

We thank the staff of the Echocardiography Room and Peritoneal Dialysis Center of The Second Affiliated Hospital of Soochow University for their help with data collection.

\section{Authors' contributions}

CT collected the patients' data and TY analyzed. JZ and FS interpreted the patients' data and wrote the manuscript. And JCC was the major contributor in auditing data and quality Prosecution. All authors have read and approved the manuscript.

\section{Funding}

This study has no funding.

\section{Availability of data and materials}

The datasets generated during the current study are not publicly available due to our research is being followed up. Our study has been registered to the Chinese Clinical Trial Registry (NO. ChiCTR1900024999), [http://www. 
medresman.org], the raw data supporting our findings will be available until the end of our study.

\section{Ethics approval and consent to participate}

This study has been approved by The Second Affiliated Hospital of Soochow University's ethics committee. And all PD patients and healthy person have signed informed consent.

\section{Consent for publication}

All individual person's data (including any individual details, images or videos) our manuscript contains have been consented in written format by patients and healthy person for publication.

\section{Competing interests}

The authors declare that they have no competing interests.

\section{Received: 10 June 2019 Accepted: 26 February 2020}

Published online: 10 March 2020

\section{References}

1. Park M, Hsu CY, Li Y, Mishra RK, Keane M, Rosas SE, Dries D, Xie D, Chen J, He J, Anderson A, Go AS, Shlipak MG. Chronic renal insufficiency cohort (CRIC) study group: associations between kidney function and subclinical cardiac abnormalities in CKD. J Am Soc Nephrol. 2012;23:1725-34.

2. Kunz K, Dimitrov Y, Muller S, Chantrel F, Hannedouche T. Uraemic cardiomyopathy. Nephrol Dial Transplant. 1998;13(Suppl 4):39-43.

3. Takase H, Dohi Y, Toriyama T, Okado T, Tanaka S, Shinbo H, Kimura G. Btype natriuretic peptide levels and cardiovascular risk in patients with diastolic dysfunction on chronic haemodialysis: cross-sectional and observational studies. Nephrol Dial Transplant. 2011;26(2):683-90.

4. Quiroga B, Villaverde M, Abad S, Vega A, Reque J, Lopez-Gomez JM. Diastolic dysfunction and high levels of new cardiac biomarkers as risk factors for cardiovascular events and mortality in hemodialysis patients. Blood Purif. 2013;36(2):98-106.

5. Chen S, Yuan J, Qiao S, Duan F, Zhang J, Wang H. Evaluation of left ventricular diastolic function by global strain rate imaging in patients with obstructive hypertrophic cardiomyopathy: a simultaneous speckle tracking echocardiography and cardiac catheterization study. Echocardiography. 2014;31(5):615-22

6. Dokainish H, Sengupta R, Pillai M, Bobek J, Lakkis N. Usefulness of new diastolic strain and strain rate indexes for the estimation of left ventricular filling pressure. Am J Cardiol. 2008;101(10):1504-9.

7. Sun JP, Yang Y, Guo R, Wang D, Lee AP, Wang XY, Lam YY, Fang F, Yang XS Yu CM. Left atrial regional phasic strain, strain rate and velocity by speckletracking echocardiography: normal values and effects of aging in a large group of normal subjects. Int J Cardiol. 2013;168(4):3473-9.

8. Hatipoglu S, Ozdemir N, Babur GG, Bakal RB, Gecmen C, Candan O, Dogan C, Unkun T. Prediction of elevated left ventricular filling pressures in patients with preserved ejection fraction using longitudinal deformation indices of the left ventricle. Eur Heart J Cardiovasc Imaging. 2015;16(10):1154-61.

9. World Health Organization: Developing an ethical framework for health ageing: report of a WHO meeting, Tübingen, Germany, 2017. http://www. who.int/iris/handle/10665/259932

10. Nagueh SF, Smiseth $O A$, Appleton CP, Byrd BF, Dokainish H, Edvardsen T, Flachskampf FA, Gillebert TC, Klein AL, Lancellotti P, Marino P, Oh JK, Popescu BA, Waggoner AD. Recommendations for the evaluation of left ventricular diastolic function by echocardiography: an update from the American Society of Echocardiography and the European Association of Cardiovascular Imaging. J Am Soc Echocardiogr. 2016:29(4):277-314.

11. Lang RM, Badano LP, Mor-Avi V, Afilalo J, Armstrong A, Ernande L, Flachskampf FA, Foster E, Goldstein SA, Kuznetsova T, Lancellotti P, Muraru D, Picard MH, Rietzschel ER, Rudski L, Spencer KT, Tsang W, Voigt JU. Recommendations for cardiac chamber quantification by echocardiography in adults: an update from the American Society of Echocardiography and the European Association of Cardiovascular Imaging. Eur Heart J Cardiovasc Imaging. 2015:16:233-70.

12. Mancia G, Fagard R, Narkiewicz K, Redon J, Zanchetti A, Bohm M, Christiaens T, Cifkova R, De Backer G, Dominiczak A, Galderisi M, Grobbee DE, Jaarsma T, Kirchhof P, Kjeldsen SE, Laurent S, Manolis AJ, Nilsson PM, Ruilope LM, Schmieder RE, Sirnes PA, Sleight P, Viigimaa M, Waeber B, Zannad F, Task Force Members. 2013 ESH/ESC guidelines for the management of arterial hypertension: the task force for the management of arterial hypertension of the European Society of Hypertension (ESH) and of the European Society of Cardiology (ESC). J Hypertens. 2013;31:1281-357.

13. Edwards NC, Moody WE, Chue CD, Ferro CJ, Townend JN, Steeds RP. Defining the natural history of uremic cardiomyopathy in chronic kidney disease: the role of cardiovascular magnetic resonance. JACC CardiovasC Imaging. 2014;7(7):703-14

14. Leibowitz D. Left ventricular hypertrophy and chronic renal insufficiency in the elderly. Cardiorenal Med. 2014;4(3-4):168-75.

15. Abraham TP, Jones M, Kazmierczak K, Liang HY, Pinheiro AC, Wagg CS, Lopaschuk GD, Szczesna-Cordary D. Diastolic dysfunction in familial hypertrophic cardiomyopathy transgenic model mice. Cardiovasc Res. 2009; 82(1):84-92

16. Lombardi R, Betocchi S, Losi MA, Tocchetti CG, Aversa M, Miranda M, D'Alessandro G, Cacace A, Ciampi Q, Chiariello M. Myocardial collagen turnover in hypertrophic cardiomyopathy. Circulation. 2003;108(12):1455-60.

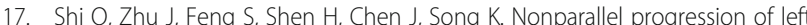
ventricular structure and function in long-term peritoneal Dialysis patients. Cardiorenal Med. 2017:7(3):198-206.

18. Wang J, Khoury DS, Thohan V, Torre-Amione G, Nagueh SF. Global diastolic strain rate for the assessment of left ventricular relaxation and filling pressures. Circulation. 2007;115(11):1376-83.

19. Wang $C$, Jiang L, Feng S, Shi Y, Shen H, Shi X, Wang Z, Zeng Y. Risk factor analysis of calcification in aortic and mitral valves in maintenance peritoneal dialysis patients. Kidney Blood Press Res. 2013;37(4-5):488-95.

20. Shi F, Feng S, Zhu J, Wu Y, Chen J. Left ventricular strain and Dyssynchrony in young and middle-aged peritoneal Dialysis patients and healthy controls: a case-matched study. Cardiorenal Med. 2018;8(4):271-84.

21. Parfrey PS, Foley RN, Harnett JD, Kent GM, Murray DC, Barre PE. Outcome and risk factors for left ventricular disorders in chronic uraemia. Nephrol Dia Transplant. 1996;11:1277-85.

22. Hayashi T, Yamada S, Iwano H, Nakabachi M, Sakakibara M, Okada K, Murai D, Nishino H, Kusunose K, Watanabe K, Ishizu T, Wakami K, Yamada H, Dohi K, Seo Y, Ohte N, Mikami T, Tsutsui H. Left ventricular global strain for estimating relaxation and filling pressure- a multicenter study. Circ J. 2016; 80(5):1163-70

23. Chan YH, Lee HF, Wu LS, Wang CL, Wu CT, Yeh YH, Ho YW, Hsu LA, Chu PH, Kuo CT. Ratio of transmitral early filling velocity to early diastolic strain rate predicts outcomes in patients with systolic heart failure. Eur Heart J Cardiovasc Imaging. 2017;18(1):79-85.

24. Kramer J, Niemann M, Liu D, Hu K, Machann W, Beer M, Wanner C, Ertl G, Weidemann F. Two-dimensional speckle tracking as a non-invasive tool for identification of myocardial fibrosis in Fabry disease. Eur Heart J. 2013;34(21): 1587-96.

25. Hoffmann R, Altiok E, Friedman Z, Becker M, Frick M. Myocardial deformation imaging by two-dimensional speckle-tracking echocardiography in comparison to late gadolinium enhancement cardiac magnetic resonance for analysis of myocardial fibrosis in severe aortic stenosis. Am J Cardiol. 2014;114(7):1083-8.

26. Wu WC, Ma H, Xie RA, Gao LJ, Tang Y, Wang H. Evaluation of left ventricular diastolic dysfunction with early systolic dysfunction using two-dimensional speckle tracking echocardiography in canine heart failure model. Echocardiography. 2016:33(4):618-27.

27. Kim H, Shin HW, Son J, Yoon HJ, Park HS, Cho YK, Han CD, Nam CW, Hur $\mathrm{SH}$, Kim YN, Kim KB. Two-dimensional strain or strain rate findings in mild to moderate diastolic dysfunction with preserved ejection fraction. Heart Vessel. 2011;26(1):39-45

28. Kimura K, Takenaka K, Ebihara A, Okano T, Uno K, Fukuda N, Ando J, Fujita $H$, Morita $H$, Yatomi $Y$, Nagai R. Speckle tracking global strain rate E/E' predicts LV filling pressure more accurately than traditional tissue Doppler E/E'. Echocardiography. 2012;29:404-10.

29. Cioffi G, Mureddu GF, Stefenelli C, de Simone G. Relationship between left ventricular geometry and left atrial size and function in patients with systemic hypertension. J Hypertens. 2004;22(8):1589-96.

30. Nagueh SF, Appleton CP, Gillebert TC, Marino PN, Oh JK, Smiseth OA, Waggoner AD, Flachskampf FA, Pellikka PA, Evangelisa A. Recommendations for the evaluation of left ventricular diastolic function by echocardiography. Eur J Echocardiogr. 2009;10(2):165-93.

31. Xu HF, He YM, Qian YX, et al. Left ventricular posterior wall thickness is an independent risk factor for paroxysmal atrial fibrillation. West Indian Med J. 2011;60:647-52. 
32. Ersoylu ZD, Tugcu A, Yildirimturk O, Aytekin V, Aytekin S. Comparison of the incidences of left ventricular hypertrophy, left ventricular diastolic

dysfunction, and arrhythmia between patients with dipper and non-dipper hypertension. Turk Kardiyol Dern Ars. 2008;36:310-7.

33. Moodley S, Balasubramanian S, Tacy TA, et al. Echocardiography-derived left ventricular outflow tract gradient and left ventricular Posterior Wall

thickening are associated with outcomes for anatomic repair in congenitally corrected transposition of the great arteries. J Am Soc Echocardiogr. 2017; 30:807-14.

\section{Publisher's Note}

Springer Nature remains neutral with regard to jurisdictional claims in published maps and institutional affiliations.

Ready to submit your research? Choose BMC and benefit from:

- fast, convenient online submission

- thorough peer review by experienced researchers in your field

- rapid publication on acceptance

- support for research data, including large and complex data types

- gold Open Access which fosters wider collaboration and increased citations

- maximum visibility for your research: over $100 \mathrm{M}$ website views per year

At $\mathrm{BMC}$, research is always in progress.

Learn more biomedcentral.com/submissions 